\title{
The Meta-Analysis About The Expression and Prognosis of Anti-Ro-52, Anti- CENP-B and AMA in Sjogren's Syndrome and Systemic Sclerosis
}

\author{
Xinyang Shao ( $\sim 1228149653 @ q q . c o m$ ) \\ Yanbing Qiu \\ Central South University Xiangya Medical College: Central South University Xiangya School of Medicine \\ Yuqin Yang \\ Central South University Xiangya Medical College: Central South University Xiangya School of Medicine \\ Yan Zhu \\ Central South University Xiangya Medical College: Central South University Xiangya School of Medicine \\ Wenling Zhang \\ Central South University Xiangya Medical College: Central South University Xiangya School of Medicine
}

Central South University Xiangya Medical College: Central South University Xiangya School of Medicine https://orcid.org/0000-0003-1929-4777

\section{Research}

Keywords: Antinuclear antibodies, Meta-analysis, Sjogren's Syndrome, Systemic Sclerosis

Posted Date: November 9th, 2021

DOI: https://doi.org/10.21203/rs.3.rs-1038140/v1

License: () (1) This work is licensed under a Creative Commons Attribution 4.0 International License. Read Full License 


\section{Abstract}

Objective This project aims to investigate the diagnostic value of anti-Ro-52, anti-CENP-B, and AMA in Sjogren's syndrome and systemic sclerosis.

Methods We constructed the Meta-analysis to evaluate the existing experimental data and obtain the advantages of the three antinuclear antibodies compared with traditional test items using specific data processing methods and evaluated their value in the diagnosis as well as the differential diagnosis of Sjogren's syndrome and systemic sclerosis. During the process of paper collection, we strictly followed the principle of PICOS to screen the literature, trying to include the literature with a large sample size, controversial and influential results which would make the results of this Meta-analysis more valuable. In this study, Revman and Stata software was used for data processing, and the forest map was drawn to analyze the difference in antibodypositive rate, age, and gender distribution, and other factors. At the same time, a funnel plot was used to evaluate the bias of literature results.

Results The positive rate of anti-Ro-52 in SS and SSC was higher than that of anti-SSB $(\mathrm{P}<0.00001)$; The positive rate of anti-CENP-B in SSc patients was higher than that in anti-SSB patients $(P<0.00001)$, but there was no significant difference in SS patients $(P=0.77)$; The positive rate of AMA in SS and SSC was significantly lower than that in ANA $(P<0.00001)$, but the expression of AMA increased in SS patients with autoimmune hepatitis. In patients with antiRo-52 positive SS and SSc associated with EBV infection, the former had a significantly increased risk of developing malignant lymphoma, while the latter had more severe symptoms of tissue fibrosis.

Conclusion The accuracy of anti-Ro-52 in the diagnosis of SS and SSC is higher. The positive rate of anti-CENP-B in the diagnosis of SSc is higher than that of anti-SSB and anti-Scl-70. SS patients with EBV infection are more likely to develop into malignant lymphoma, while SSc patients with EBV infection have increased skin fibrosis and inflammation.

\section{Introduction}

Sjogren's syndrome (SS) and systemic sclerosis (SSC) are both chronic progressive autoimmune diseases, The former is mainly characterized by dryness of exocrine glands, with representative symptoms of dry eyes and dry mouth; The latter mainly manifested as skin fibrosis and chronic inflammation. When the two diseases worsen to a certain extent, they can affect the lung, kidney, heart, and other important organs[1]. However, due to the strong heterogeneity of SS and SSc and the wide expression spectrum of antinuclear antibodies, it is necessary to combine body fluid, pathological biopsy, CT, and other auxiliary examinations in the diagnosis process, which make the diagnostic efficiency low[2]. The purpose of this meta-analysis is to find out antinuclear antibody indicators with higher positive rates and better accuracy, which can simplify the diagnosis process of SS and SSc.

Recent data showed that the proportion of SS with autoimmune liver disease (ALD) has reached 33\%, and the incidence of other complications such as thyroid disease, arthritis, vasculitis, pulmonary fibrosis, and ankylosing spondylitis also increased slightly; The main complication of SSc is pulmonary hypertension, which is also the main cause of death of SSc patients[3]. The mortality of SSc patients has not decreased significantly in the recent 30 years due to the lack of improvement in diagnostic efficiency and prognosis. The routine antinuclear antibody detection items in hospitals mainly include antiSSA, anti-SSB, and Jo-1, etc., which can not distinguish SS and SSC from other common autoimmune diseases (such as systemic lupus erythematosus, rheumatoid arthritis, etc.) and some inflammatory reactions with elevated antinuclear antibody[4]. Therefore, it is imperative to find more accurate antinuclear antibody detection items.

In this meta-analysis, we evaluated the positive rate and accuracy of anti-Ro-52, anti-CENP-B, and AMA in SS and SSC. Anti-Ro-52, as an existing examination item in some hospitals, increases in some autoimmune diseases and inflammatory reactions. This paper focuses on the difference between anti-Ro-52 in SS, SSc, and other autoimmune diseases, discussing its value in the differential diagnosis of SS and SSc. Recent studies have shown that the positive rate of anti-CENP-B in SS and SSC is higher than that of anti-SSB, which is a more easily detected anti-nuclear antibody index[1]. At the same time, in SSc patients with pulmonary hypertension(PAH), compared with the traditional detection index, the titer of anti-CENP-B decreased while anti-Scl-70 has no change, which is also helpful for the classification of SSc. There are few studies on AMA, but there is still literature showing that the positive rate of AMA in SS with ALD is significantly higher than that of ANA, which is helpful to assess the prognosis of SS patients[5].

\section{Materials And Methods}

\subsection{Revman Statistic Analysis}

\subsubsection{Forest plot analysis}

In this study, we collected the number of target antibody-positive samples, the number of antibody-positive samples in the control group, and the total number of samples for the different analyses of the positive rate of antinuclear antibody expression. We use the data processing software Review Manager 5.4 to draw the forest plots. Because the recorded data was selected as a binary variable, we chose the more appropriate relative risk (RR) as the effect quantity index in the prospective study. In the process of data entry, we evaluate the risk of literature with different results and abandon the literature data with high-risk factors. The remaining data were drawn forest map, and the components that black diamond and the invalid line did not intersect were selected for result analysis. Because the default value of Revman software is "adverse event" when drawing forest map, we modify the abscissa to "favors control" on the left and "favors treatment" on the right to ensure the correctness of the forest map[3].

2.1.2 Funnel plot analysis 
In this study, we used the funnel plot drawn by Revman 5.4 to evaluate the publication bias of the articles included in each group. Studies with a small sample size and low precision will be symmetrically distributed at the bottom of the funnel plot, while studies with a large sample size and high precision were distributed in the upper part of the funnel plot and close to the middle line. In principle, the width of the funnel plot narrows with the increase of the accuracy of the estimator. When the funnel plot is asymmetric, the publication bias exists. To increase the objectivity of the funnel chart, more than nine papers per chart are needed to make the evaluation results meaningful.

\subsection{Stata MP-64 Statistic Analysis}

In this study, Stata MP-64 software was used to complete the gender subgroup analysis, clinical characteristics distribution, and sensitivity analysis of patients with positive expression of specific antibodies. The chart of Stata sensitivity analysis better shows the difference of effect scale of each article, to get the main research influencing the analysis results, and find out the leading factors influencing the conclusion of the topic in the corresponding articles. The software can combine the subgroup analysis and clinical specific distribution map of different antinuclear antibodies, and comprehensively display the expression characteristics of each kind of antibody.

\subsection{Paper Screening}

In this study, PubMed, Web of Science, Cochrane Library, and Embase databases were used to preliminarily search literature according to keywords(total 925), and basic information of literature (title, DOI, PMID, author, publication time, journal name, impact factor) was recorded. Repetitive literature (343 duplicates) was excluded according to PMID. According to the principle called PICO (population, intervention, comparison, outcome) of meta-analysis, three rounds of screening were carried out for the preliminary retrieved literature. For the first round of screening, we read the title and abstract of the literature, recruit the literature including complete research keywords, and initially record the key information (research main content, target population, target disease, target antibody), and preliminarily exclude the literature with inconsistent content, population, disease type and antibody (242 excluded). In the second round, the left literature was searched for full text according to DOI serial number and excluded the literature with unaccessible full text (208 excluded).

During the third round of screening, we skimmed the articles and recorded the types of antibodies, disease types, positive and negative samples of antibody expression, intervention measures, antibody detection methods, and clinical characteristics of antibody-positive patients. We retained the literature with specific data and excluded those with incomplete or inconsistent data with the target antibody (44 excluded). We read through the remaining articles that meet the requirements, and extract the detailed information needed for the study (such as the coexistence and expression of antibodies, disease classification and prognosis of patients, etc.) (Figure 2-1)

\section{Results}

\subsection{The Diagnostic Significance of anti-Ro-52 in SS}

\subsubsection{Difference of positive rate between anti-Ro-52 and anti-SSB in SS patients}

To study the superiority of the positive rate of anti-Ro-52 expression in patients with Sjogren's syndrome (SS), 22 related literature were selected. The number of anti-Ro-52 positive patients, the total number of anti-Ro-52 group patients, the number of anti-SSB positive patients in the control group, and the total number of control group patients in the study samples were collected and recorded. After the software processing, 13 studies intersected with the invalid line, of which 2 studies (Ben Eli H 2020, Wahren M 1997) were biased towards anti-SSB, and the remaining 9 studies were biased towards the side beneficial to anti-Ro-52 although they intersected with the invalid line[4].

The total sample size of the research group was 1019, and that of anti-Ro-52 positive patients was 555 . The overall positive rate was $54.47 \%$, which was higher than $36.16 \%$ in the control group ${ }^{[5,6]}$. The overall forest plots analysis results did not intersect with the invalid line and were located on the right side of the invalid line $(\mathrm{RR}=1.52[1.39,1.67])$, showing that the positive expression rate of anti-Ro-52 in SS patients was significantly higher than that of traditional detection item anti-SSB ${ }^{[7,8]}$, and had statistical significance $(95 \% \mathrm{Cl}, \mathrm{P}<0.00001)$ (Figure $\left.3-1\right)$

\subsubsection{Distribution of clinical manifestations in anti-Ro-52 positive SS patients}

Five studies(Tengnér P 1998, Halse AK 2000, Halse A 1999, Sujau I 2014, Fujimoto M 1997) mentioned the clinical characteristics of anti-Ro-52(+) SS patients and counted the number of specific samples of each phenotype. It is worth noting that patients classified as severe Sjogren's syndrome (severe SS) only appear in anti-Ro-52(+) patients, and the incidence rate is as high as 35\% (in this literature, SS patients with severe organ failure or long-term pain symptoms or arthritis or myositis are defined as severe SS patients), while all anti-Ro-52 negative patients are defined as moderate SS[9]. These results indicate that anti-Ro-52 can be used as a potential indicator of severe disease or poor prognosis in patients with SS, and provide some guidance for the medication and treatment of patients.

For all SS patients with anti-Ro-52(+), pulmonary fibrosis is the most prominent complication, with an incidence rate as high as $70 \%$, which is much higher than that of arthritis and thyroid involvement, and more serious complications such as renal crisis or heart involvement are rarely mentioned in the literature screened in this study, indicating that the overall prognosis of SS patients with anti-Ro-52(+) is relatively considerable[10]. However, we need to pay attention to the maintenance and treatment of the respiratory system to improve the prognosis of patients[11]. (Figure 3-2)

3.1.3 Age Distribution of anti-Ro-52(+) SS patients 
As shown in Figure 3-3, three pieces of literature mentioned the age information of anti-Ro-52(+) SS patients at the time of diagnosis. Most anti-Ro-52(+) SS patients were diagnosed before 45 years old, and only a small number of patients were diagnosed after 45 years old[12]. It can be inferred that anti-Ro52(+) SS patients may have more serious symptoms, which speeds up the process of diagnosis and further consolidates the results of the previous histogram, These results suggest that anti-Ro-52 may be an indicator of poor prognosis in SS patients.(Figure 3-3)

\subsubsection{The result of funnel plot analysis}

For funnel plot analysis, more than 9 articles need to be included for being statistically significant. A total of 22 articles were included in this study. The sample size and analysis results of each article were analyzed by using Revman software. As shown in Figure 3-3, 20 papers are distributed in the middle top of the funnel chart, which indicates that most of the studies have a large sample size and high accuracy. The funnel plot showed a symmetrical distribution, indicating that there was no publication bias, the level of included literature was high, and the results of data analysis were reliable.(Figure 3-4)

\subsection{The Diagnostic Significance of anti-CENP-B in SS}

\subsubsection{Difference of positive rate between anti-CENP-B and anti-SSB in SS patients}

As a popular antinuclear antibody to detect autoimmune diseases, the expression of anti-CENP-B in SS patients also has certain characteristics. In this group, we included 9 studies with corresponding data, recorded the number of SS patients with positive expression of anti-CENP-B, the total number of patients studied, the number of patients with positive expression of anti-SSB in the control group, and the total number of patients in the control group, and input the data into Revman for forest map analysis[13]. As shown in Figure 3-4, the results of four studies intersect with the invalid line, three of which are in favor of the side against SSB, and only one study is slightly in favor of the side of anti-CENP-B.

The total sample size of the group was 781 , the positive rate of the experimental group was $21.51 \%$, and the positive rate of the control group was $23.16 \%$. After meta-analysis, the result intersected with the invalid line $(\mathrm{Cl} 0.97[0.81,1.17])$, and there was no significant statistical difference $(P=0.77)$, indicating that anti-CENP-B had no obvious advantage over traditional anti-SSB detection in the positive rate of expression[14, 15]. (Figure 3-5)

\subsubsection{The result of funnel plot analysis}

The research group has included 9 pieces of literature, as shown in Figure 3-6. Most of the literature is distributed in the middle and lower part of the funnel map, indicating that the sample size of most studies is small and the accuracy is not good. However, the 9 studies are symmetrical distribution relative to the axis in funnel map, without obvious deviation, indicating that the group has no published bias, and the overall analysis results are more feasible. But we should optimize the quality of the selected research, and eliminate the research with low precision and poor quality.(Figure 3-6)

\subsection{The Diagnostic Significance of AMA in SS}

In the AMA group, we included six studies, none of which intersected the invalid line, and all of them were on the left side of the invalid line, that is, the results of all studies were biased to the side of ana. The total sample size of this research group was 564 . The positive rate of AMA was $15.25 \%$, and that of ANA was $76.24 \%$. The overall meta-analysis results of the AMA group as a whole did not intersect with the invalid line and located on the left[16], indicating that the positive rate of ANA in SS patients was significantly higher than that of AMA, and the results were statistically significant $(\mathrm{Cl} 0.20$ [0.16,0.25], $\mathrm{P}<$ 0.00001). Therefore, AMA was not superior to ANA in the diagnosis of SS patients. However, studies have shown that for SS patients with autoimmune liver disease, AMA titer is significantly increased, and the content is significantly higher than Ana, which has a certain guiding significance for the diagnosis and differential diagnosis of autoimmune hepatitis[17]. (Figure 3-7)

\subsection{The Diagnostic Significance of anti-Ro-52 in SSc}

\subsubsection{Difference of positive rate between anti-Ro-52 and anti-SSB/anti-Scl-70 in SSc}

To study the role of anti-Ro-52 in the diagnosis of SSc patients, 24 eligible studies were selected. The total sample size of our group was 5850 , the number of anti-Ro-52 positive SSc patients was 1590 , the overall positive rate was $27.18 \%$, while in the control group, there were only 569 anti-SSB/anti-Scl-70 positive SSc patients, the positive rate was only $9.73 \%$. Therefore, the positive rate of the experimental group was significantly higher than that of the control group, which was conducive to the further analysis of its statistical significance by using forest plots.

After processing by Revman software, as shown in Figure 3-8, 9 of 24 studies intersected with the invalid line, and only 1 of these 9 studies (Liu C 2019) slightly biased to the anti-SSB side, and the remaining 23 literature results were all favorable for anti-Ro-52 antibody ${ }^{[18,19]}$. In the overall meta-analysis results, the total RR value did not intersect with the invalid line and was located on the right side of the invalid line $(r=2.79$ [2.56,3.04]), indicating that the positive rate of anti-Ro-52 expression in SSc patients was significantly higher than that in traditional antinuclear antibody detection items anti-SSB and anti-Scl-70, and the results were statistically significant $(\mathrm{P}<0.00001)$. It can be seen that anti-Ro-52 is superior to anti-SSB/anti-Scl-70 in positive rate in the detection of $\mathrm{SSC}^{[20,21,22]}$, which can be used as a new indicator of SSC detection.(Figure 3-8)

\subsubsection{Distribution of clinical manifestations of anti-Ro-52(+) SSc patients}

In the literature on the relationship between anti-Ro-52 and SSc patients, a total of 6 pieces of literature have data support for the clinical manifestations and incidence of anti-Ro-52 positive patients[23, 24]. Among all the common clinical complications, Raynaud's phenomenon and gastrointestinal involvement were the most common, with an average incidence of $62.65 \%$ and $50.43 \%$ respectively. The second is telangiectasia (42.57\%) and pulmonary 
fibrosis and pulmonary hypertension (47.55\%)[25]. The average incidence of this symptom is not only high, but also mentioned in almost every literature, and the variance is less than 0.2 , indicating that the results of each literature fluctuate less, and the incidence is relatively stable and reliable. The incidence of hand deformity and arthritis is about 30\%[26], only a few literature mentioned this symptom, and the symptoms in SSc patients are not serious. The average incidence of disease crises such as renal crisis and cardiac involvement was less than 3\%, indicating that the prognosis of anti-Ro-52 positive SSc patients was better[27], and the probability of death factors was very low. However, as with SS patients, the incidence of pulmonary complications in antiRo-52 positive SSc patients is higher, which has a certain role in the treatment of symptoms. At the same time, the vascular complications of anti-Ro-52 positive SSc patients are also very common, which should be paid attention to during the medical treatment.(Table 3-1)

\subsubsection{Distribution of disease types in anti-Ro-52(+) SSc patients}

Systemic sclerosis (SSc) can be divided into localized sclerosis(IcSSc) and diffuse sclerosis(dcSSc). In SSc patients with positive expression of anti-Ro-52, the incidence of IcSSc and dcSSc is also different[28]. Among the relevant literature screened out in this study, 6 pieces of literature have expounded relevant views and provided corresponding data, as shown in Table 3-2. Among them, $61.21 \%$ of anti-Ro-52 positive SSc patients are IcSSc, only $38.45 \%$ of anti-Ro-52 positive SSc patients are dcSSc, and $1.55 \%$ of patients are defined as sine scleroderma, i.e. systemic sclerosis without skin sclerosis symptoms[29]. It can be seen that when the anti-Ro-52 expression is positive, IcSSc is dominant, but compared with the overall SSc patients, the proportion of IcSSc (68.42\%) is not significantly reduced, so anti-Ro-52 is not enough to provide a guarantee for a good prognosis[30]. (Table 3-2)

\subsubsection{The result of funnel plot analysis}

A total of 24 pieces of related literature were included in this research group. As shown in Figure 3-9, 22 literature were located in the upper and middle parts of the funnel chart, which means the research with large sample size and high accuracy. Two pieces of literature were located in the lower and middle parts of the chart, which means the accuracy is poor compared with other literature. The funnel plot is symmetrical, but slightly skewed to the right, indicating that there is a slight publication bias, but the overall accuracy of the literature is good and the quality is high, so the overall research results are highly reliable.(Figure 3-9)

\subsection{The Diagnostic Significance of anti-CENP-B in SSc}

3.5.1 Difference of positive rate between anti-CENP-B and anti-SSB/anti-Scl-70 in SSc

In the study group of the therapeutic significance of anti-CENP-B for SSc patients, 42 articles met our research requirements, and the total sample size reached 8273 cases. Among them, 3218 cases were anti-CENP-B positive, and the overall positive rate was $38.90 \%$. The positive rate of the control group was only $22.86 \%$. The positive rate of the experimental group was significantly higher than that of the control group, It provides basic data support for the subsequent meta-analysis of forest plots drawing[31].

After the data processing of Revman software, 14 of the 42 studies intersected with the invalid line, and the results of 7 works of literature were biased to the side of anti-SSB and anti-Scl-70. The results of the four studies were in the middle of the invalid line, and there was no difference between the experimental group and the control group. The remaining 31 results were all in favor of the anti-CENP-B side. The overall results of the meta-analysis showed that RR was $1.71[1.63,1.79]$, which did not intersect with the invalid line and was on the right side of the invalid line, indicating that the positive rate of anti-CENP-B expression in SSc patients was significantly higher than that of anti-SSB and anti-Scl-70, and the results were statistically significant ( $\mathrm{P}<$ 0.00001). Therefore, anti-CENP-B is superior to anti-SSB and anti-Scl-70 in the detection positive rate[32, 33, 34], which can be used as a new basis for the diagnosis of SSc patients.(Figure 3-10)

\subsubsection{Distribution of clinical manifestations in anti-CENP-B(+) SSc patients}

In the literature screened by our group, we selected 10 articles with relevant data support to make statistics and comparisons on the occurrence probability of clinical manifestations of anti-CENP-B positive SSc patients. As shown in Table 3-3, gastrointestinal involvement had the highest incidence of symptoms (46.44\%)[35], followed by telangiectasia (45.25\%) and Raynaud's phenomenon (44.23\%)[36, 37]. However, the data of different studies on these two phenomena were quite different, so the reliability was not high. Pulmonary fibrosis and pulmonary hypertension are still the most common complications mentioned in most articles, but the incidence rate is only $33.48 \%$. Compared with anti-Ro-52 positive SSc patients, the incidence of disease crisis was higher in anti-CENP-B positive SSc patients (renal crisis $1.55 \%$ vs. $7.88 \%$, cardiac involvement $2.98 \%$ vs. $13.18 \%$ ). Therefore, the positive expression of anti-CENP-B may indicate the poor prognosis of SSc patients[38, 39].

Our group also analyzed the age of diagnosis and course of disease of SSc patients with positive anti-CENP-B. The age of diagnosis was 45.0 years old, which was not significantly different from the average age of diagnosis of SSc patients of 40.1 years old[40]. The course of the disease was 15.6 years, which was significantly longer than the average course of 3.5 years. In other circumstances the symptoms of anti-CENP-B positive patients are not obvious, leading to delayed treatment, delayed age of diagnosis, and prolonged course of disease[41]. (Table 3-3)

\subsubsection{Distribution of disease types in anti-CENP-B(+) SSc patients}

In the study of our group, there are 9 literature that mentioned the classification characteristics of anti-CENP-B(+) SSc patients and provided relevant data. The IcSSc patients accounted for $85.13 \%$, which was much higher than the overall IcSSC accounted for $68.42 \%$. It explained the characteristics of delayed diagnosis and the long course of disease in patients with positive anti-CENP-B expression[42]. Because the symptoms of most mild IcSSc are not obvious, it is common to cause misdiagnosis. The patients choose to see a doctor when the symptoms become too serious, thus delaying the best treatment 
opportunity, resulting in the increased incidence of disease crisis, poor prognosis, and increased mortality[43]. Therefore, anti-CENP-B can be used as an important indicator for early diagnosis of SSC, to prevent missed diagnosis and misdiagnosis, and to take timely measures for relevant patients, which can effectively avoid the deterioration of the disease and improve the prognosis of patients[44].(Table 3-4)

\subsubsection{The result of funnel plot analysis}

As shown in Figure 3-11, most of the 42 papers in our group are distributed at the top of the middle of the funnel plot, which is of large sample size and high precision. Only 5 papers are distributed at the right side of the middle of the funnel plot, which is smaller than most of the studies, but all of them are close to the middle line. The funnel plot is symmetrical, and there is no obvious deviation, which indicates that there is no publication bias, the overall research accuracy is high, the quality of literature is good, and the research results are reliable.(Figure 3-11)

\subsection{The Diagnostic Significance of AMA in SSc}

The positive rate of AMA and ANA were compared in 7 selected literature. Four of the results intersect with the invalid line, three of them are biased to the side of AMA, and one is biased to the side of ANA. All the results that do not intersect with the invalid line are on the left. The total sample size reached 1191 cases, the positive rate of AMA was $4.03 \%$, and the positive rate of ANA was $82.92 \%$. After forest plots analysis, the RR value was 0.04 [0.03,0.06], which was located on the left side of the invalid line. Therefore, the positive rate of AMA was far lower than that of ANA[45], and the result was statistically significant $(P<0.00001)$. (Figure 3-12)

3.7 Comparison of disease type distribution between Ro-52(+) and CENP-B(+) SSc

As shown in Figure 3-13, the proportion of IcSSc in anti-CENP-B(+) SSc patients is significantly higher than that in the anti-Ro-52 positive group. Based on the above analysis, anti-Ro-52 positive as an indicator of poor prognosis may tend to lead to more severe dcSSc, while anti-CENP-B is more likely to lead to mild IcSSc, leading to missed diagnosis and misdiagnosis, delaying the diagnosis time, prolonging the course of the disease, and affecting the prognosis of patients[46].(Figure 3-13)

\subsection{Coexistence of antibodies in SSc patients}

In SSc patients, the coexistence probability of anti-Ro-52 and anti-Ro-60, anti-CENP-B, and anti-SSB is more than 30\%[42], which provides a good basis for improving the accuracy of SSC detection and the judgment of clinical manifestations. Through the combination of traditional detection indicators and new indicators, the diagnostic efficiency of SSC can be improved and the prognosis of patients can be improved.(Table 3-5)

\subsection{The Effect of EBV infection on anti-Ro-52(+) SS and SSc patients}

\subsubsection{The Effect of EBV infection on anti-Ro-52(+) SS patients}

For SS patients with positive anti-Ro-52 expression, EBV infection will greatly increase the risk of SS transforming into Hodgkin's lymphoma. The virus infiltration site is usually the gland with abnormal monoclonal amplification of B cells[48]. In the past 20 years, nearly $14 \%$ of SS patients developed into malignant lymphomas. The mechanism of EBV infection-related SS patients may be related to excessive T cell costimulation, impaired specific T cell response to EBV, cross-reaction of anti-EBV antibody, inhibition of B cell apoptosis, and other factors[49]. The detection rate of EB-DNA in salivary glands of anti-Ro-52(+) SS patients was significantly increased (78\%), while the detection rate of EB-DNA in salivary glands of normal people was only $13 \%[50]$.

\subsubsection{The Effect of EBV infection on anti-Ro-52(+) SSc patients}

EBV infection contributes to the deterioration of the disease in anti-Ro-52(+) SSc patients. The main mechanism is that EBV can infect dermal fibroblasts, regulating the innate immune response of infected fibroblasts and inducing them to transform into a typical Pro fibrotic phenotype. EBV viral transcripts and proteins play an important role in this process[51]. For example, EBV proteins like ZEBRA, BFRF1, and BFLF2 are more significantly expressed in nonIcSSc patients, which can induce chronic inflammation and fibrosis of the skin. Studies have shown that EBV cleavage antigen is detected in scleroderma skin vessels[52], suggesting that endothelial cells may be the target of EBV infection in scleroderma skin. Compared with healthy EBV carriers, the load of EBV-DNA in peripheral blood, plasma, and circulating monocytes of scleroderma patients are significantly increased[53]. These results suggest that the upregulation of EB-DNA loading may be a potential biomarker for scleroderma vasculopathy.

\section{Discussion}

In this paper, we conducted a meta-analysis on the value of anti-Ro-52, anti-CENP-B, and AMA in the early diagnosis and prognosis of patients with SS and SSc. For SS patients, the positive rate of anti-Ro-52 was significantly higher than that of anti-SSB. Previous studies showed that common autoimmune diseases easily confused with SS, such as systemic lupus erythematosus (SLE) and rheumatoid arthritis (RF), showed high expression of anti-SSB and low or no expression of anti-Ro-52. This data can effectively distinguish SS from SLE, RF, and other diseases because anti-Ro-52 and anti-SSB in SS patients have the characteristics of "double high" expression [12]. We conducted in-depth statistics on the clinical characteristics and disease classification of antiRo-52(+) SS patients and found that patients defined as "severe Sjogren's syndrome" only appeared in anti-Ro-52 positive patients, indicating that anti-Ro-52 played a role in aggravating and accelerating the disease process, which can explore the relevant molecular mechanism in future research, and optimize the diagnosis and treatment process of patients [24]. The positive rate of anti-CENP-B expression in SS patients in this study has a large gap, which leads to the final result that there is no statistical difference between the positive rate of anti-CENP-B and anti-SSB expression. Therefore, the characteristics of SS patients recruited in the literature should be investigated and classified, and the statistical results obtained from this will be more convincing. At the same 
time, the positive rate of anti-CENP-B in this group was only $21.51 \%$, which needs to be verified by expanding the sample size. We can also further study the specificity of its expression in SS patients and its significance in disease classification.

In SSc patients, the positive rates of anti-Ro-52 and anti-CENP-B were higher than those of anti-SSB or anti-Scl-70. Different from the low expression of antiRo-52 and high expression of anti-SSB in SLE and RF patients with common autoimmune diseases, SSc patients have high levels of anti-Ro-52, anti-SSB, anti-Scl-70, and even anti-CENP-B[33]. It is worth mentioning that the proportion of IcSSc in anti-Ro-52 positive patients decreased slightly (61.21\% vs. $68.42 \%$ ), which has a certain role in promoting the disease progression of SSc. It is necessary to continue to expand the sample size for statistical analysis. The proportion of IcSSc patients in anti-CENP-B positive SSc patients was significantly increased (85.13\% vs. $68.42 \%)$, but the age of diagnosis and disease progression of this group of patients were later and longer than that of the overall SSc patients, indicating that most of the patients transformed into IcSSc delayed the best time of treatment due to the lack of obvious onset symptoms and easily confused with other diseases. The incidence of disease crisis in the anti-CENP-B positive group was higher than that in the anti-Ro-52 positive group[46]. Jing Zhao et al. showed that the increase of anti-CENP-B in SSc patients was positively correlated with anti-tubulin-a-1C, and the high concentration of the latter would lead to a significant increase of anti-CENP-B, and the anti-tubulin antibody was only increased in SSc patients at present. The follow-up study can take this as a breakthrough point to further study the molecular mechanism of SSc.

The positive rate of AMA expression in SS and SSc patients is far lower than that of ANA, but some studies have shown that the expression of AMA in SS with ALT is significantly increased, and the positive rate is higher than that of ANA. Recent studies showed that AMA-M2 was $94.29 \%$ (33/35) in SS patients with ALT, and only $10.62 \%(12 / 113)$ in normal SS patients[28]. We can make further research on this subtype of AMA, and explore the rules of other subtypes of AMA in the diagnosis of SS subtypes.

Many articles have mentioned the mechanism and influence of EBV infection on the disease progression of anti-Ro-52 positive SS and SSc. EBV in SS patients mainly interferes with the normal immune prevention and control mechanism, promotes B cell monoclonal, disturbs the role of specific T cells, and greatly increases the possibility of SS developing into Hodgkin's lymphoma. The molecular mechanism of EBV-induced SS has been described in some literature. It is believed that anti-Ro-52 and EBNA-1 tend the same structure on the exocrine gland cells, which can form ectopic lymphoid structure (ELS) on the salivary gland, thus contributing to the local growth and differentiation of disease-specific self-reactive B cells[54]. Follow-up studies can further explore the molecular mechanism of EBV infection, develop targeted therapy and reduce the possibility of SS transforming into cancer. In anti-Ro-52 and anti-CENPB positive SSc patients, pulmonary fibrosis is one of the most common complications, and EBV infection can accelerate fibroblast fibrosis and worsen the disease process through specific viral transcripts and proteins[52]. Farina A et al. have shown that infectious EBV can induce monocytes of SSc patients to express TLR8 in vitro, which provides preliminary evidence for monocytes of SSc patients to infect EBV[55]. It can link EBV with the activation of IFN innate immune response in the pathogenesis of SSc, and we can further identify the types of virus products that cause the increase of TLR8, To improve the molecular mechanism of chronic skin inflammation caused by EBV[56, 57].

The limitations of this meta-analysis are mainly due to the relatively small sample size and the limited literature that meets the screening conditions. Some results need to be further confirmed by expanding the sample size.

\section{Conclusion}

The accuracy of anti-Ro-52 in the diagnosis of SS and SSC is higher. The positive rate of anti-CENP-B in the diagnosis of SSc is higher than that of anti-SSB and anti-Scl-70. SS patients with EBV infection are more likely to develop into malignant lymphoma, while SSc patients with EBV infection have increased skin fibrosis and inflammation.

\section{Declarations}

\section{Acknowledgement}

Throughout the writing process of this dissertation I have received a great deal of support and assistance. Sponsorship for this study were funded by Laboratory Department of Xiangya Medical School. All named authors meet the International Committee of Medical Journal Editors (ICMJE) criteria for authorship for this article, take responsibility for the integrity of the work as a whole, and have given their approval for this version to be published.

All authors contributed to the study conception and design. I would first like to acknowledge Professor, Zhang Wenling, for her guidance through each stage of the process. I would also like to thank all my tutors from the Laboratory Department of Xiangya Medical School, who provided me with the tools I needed to choose right direction and successfully complete my research.

\section{Funding}

No funding or sponsorship was received for this study or publication of this article.

\section{Availability of data and material}

All data and material that support the findings of this study are available from the corresponding author upon reasonable request.

\section{Code availability}

Not applicable. 


\section{Conflict of interest}

We declare that we have no financial and personal relationship with other people or organizations that can inappropriately influence our work. There is no professional or other personal interest of any nature or kind in any product, service or company that could be constructed as influencing the position presented in, or the manuscript entitled.

\section{Authors' contributions}

Xinyang Shao and Wenling Zhang contributed to the conception of the study.

Xinyang Shao performed the data analysis and wrote the manuscript;

Yanbin Qiu, Yuqin Yang and Yan Zhu helped perform the analysis with constructive discussions.

\section{Ethics approval}

Not applicable.

\section{Consent to participate}

Not applicable.

\section{Consent for publication}

Not applicable.

\section{References}

1. Abolbashari S, Ghayour-Mobarhan M, Ebrahimi M, et al. The role of human T-lymphotropic virus (HTLV) in cardiovascular diseases: A review of literature[J]. ARYA Atheroscler, 2018,14(4):183-187.

2. Bureta $\mathrm{CA}$, Abematsu $\mathrm{M}$, Tominaga $\mathrm{H}$, et al. Hypertrophic spinal pachymeningitis associated with human T-cell lymphotrophic virus-1 infection and Sjogren's syndrome: A case report and brief literature review[J]. Int J Surg Case Rep, 2018, 45(2):22-28.

3. Nakamura H, Shimizu T, Kawakami A. Role of Viral Infections in the Pathogenesis of Sjögren's Syndrome: Different Characteristics of Epstein-Barr Virus and HTLV-1[J]. J Clin Med, 2020, 9(5):1459.

4. Yamamoto AM, Amoura Z, Johannet $\mathrm{C}$, et al. Quantitative radioligand assays using de novo-synthesized recombinant autoantigens in connective tissue diseases: new tools to approach the pathogenic significance of anti-RNP antibodies in rheumatic diseases[J]. Arthritis Rheum, 2000, 43(3):68998.

5. Trier $\mathrm{NH}$, Nielsen $\emptyset$, Friis T, et al. Comparison of antibody assays for detection of autoantibodies to Ro 52 , Ro 60 and La associated with primary Sjögren's syndrome[J]. J Immunol Method, 2016, 433(11):44-50.

6. Theander E, Jonsson R, Sjöström B, et al. Prediction of Sjögren's Syndrome Years Before Diagnosis and Identification of Patients With Early Onset and Severe Disease Course by Autoantibody Profiling[J]. Arthritis Rheumatol, 2015, 67(9):2427-36.

7. Croia C, Astorri E, Murray-Brown W, et al. Implication of Epstein-Barr virus infection in disease-specific autoreactive B cell activation in ectopic lymphoid structures of Sjögren's syndrome[J]. Arthritis Rheumatol, 2014, 66(9):2545-57.

8. Birnbaum J, Atri NM, Baer AN, et al. Relationship Between Neuromyelitis Optica Spectrum Disorder and Sjögren's Syndrome: Central Nervous System Extraglandular Disease or Unrelated, Co-Occurring Autoimmunity[J]. Arthritis Care Res (Hoboken), 2017, 69(7):1069-1075.

9. Ben-Eli H, Solomon A, Aframian DJ, et al. Serological and hematological characteristics of Sjogren's syndrome and dry eye syndrome patients using a novel immune serology technique[J]. PLoS One, 2020, 15(12):e0244712.

10. Alsaed OS, Alamlih LI, Al-Radideh O, et al. Clinical utility of ANA-ELISA vs ANA-immunofluorescence in connective tissue diseases[J]. Sci Rep, 2021, 11(1):8229.

11. Scholz J, Grossmann K, Knütter I, et al. Second generation analysis of antinuclear antibody (ANA) by combination of screening and confirmatory testing[J]. Clin Chem Lab Med, 2015, 53(12):1991-2002.

12. Bremer HD, Lattwein $E$, Renneker S, et al. Identification of specific antinuclear antibodies in dogs using a line immunoassay and enzyme-linked immunosorbent assay[J]. Vet Immunol Immunopathol, 2015, 168(3-4):233-41.

13. Kajio N, Takeshita M, Suzuki K, et al. Anti-centromere antibodies target centromere-kinetochore macrocomplex: a comprehensive autoantigen profiling[J]. Ann Rheum Dis, 2020, 80(5):651-9.

14. Tanaka N, Muro Y, Suzuki Y,et al. Anticentromere antibody-positive primary Sjögren's syndrome: Epitope analysis of a subset of anticentromere antibody-positive patients[J]. Mod Rheumatol, 2017, 27(1):115-121.

15. Takeshita M, Suzuki K, Kaneda Y, et al. Antigen-driven selection of antibodies against SSA, SSB and the centromere 'complex', including a novel antigen, MIS12 complex, in human salivary glands[J]. Ann Rheum Dis, 2020, 79(1):150-158. 
16. Tanaka A, Nezu S, Uegaki S, et al. The clinical significance of IgA antimitochondrial antibodies in sera and saliva in primary biliary cirrhosis[J]. Ann $\mathrm{N} \mathrm{Y}$ Acad Sci, 2007, 1107(13):259-70.

17. Watt FE, James OF, Jones DE. Patterns of autoimmunity in primary biliary cirrhosis patients and their families: a population-based cohort study[J]. QJM, 2004, 97(7):397-406.

18. Dixit S, Kalkur C, Sattur AP, et al. Scleroderma and dentistry: Two case reports[J]. J Med Case Rep, 2016, $10(1): 297$.

19. Sujau I, Ng CT, Sthaneshwar P, et al. Clinical and autoantibody profile in systemic sclerosis: baseline characteristics from a West Malaysian cohort[J]. Int J Rheum Dis, 2015, 18(4):459-65.

20. Rao AG, Farheen SS, Reddy UD, et al. Anti-RO 52-positive systemic sclerosis sine scleroderma with multisystem involvement and recurrent vasculitis[J]. Indian J Dermatol Venereol Leprol, 2018,;84(5):607-610.

21. Patterson KA, Roberts-Thomson PJ, Lester S, et al. Interpretation of an Extended Autoantibody Profile in a Well-Characterized Australian Systemic Sclerosis (Scleroderma) Cohort Using Principal Components Analysis[J]. Arthritis Rheumatol, 2015, 67(12):3234-44.

22. Oliva Menacho JE, Arroyo-Acevedo JL, Oliva-Candela JA, et al. Staining of antinuclear antibodies and antibodies against removable nuclear antigens in connective tissue diseases[J]. Allergol Immunopathol (Madr), 2020, 48(1):18-25.

23. Liu C, Hou Y, Yang Y, et al. Evaluation of a commercial immunoassay for autoantibodies in Chinese Han systemic sclerosis population[J]. Clin Chim Acta, 2019, 491(2):121-125.

24. Chang WS, Schollum J, White DH, et al. A cross-sectional study of autoantibody profiles in the Waikato systemic sclerosis cohort, New Zealand[J]. Clin Rheumatol, 2015, 34(11):1921-7.

25. Villalta D, Imbastaro T, Di Giovanni S, et al. Diagnostic accuracy and predictive value of extended autoantibody profile in systemic sclerosis[J]. Autoimmun Rev, 2012, 12(2):114-20.

26. Foocharoen $\mathrm{C}$, Watcharenwong P, Netwijitpan S, et al. Relevance of clinical and autoantibody profiles in systemic sclerosis among Thais[J]. Int $\mathrm{J}$ Rheum Dis, 2017, 20(10):1572-1581.

27. Fujimoto M, Shimozuma M, Yazawa N, et al. Prevalence and clinical relevance of 52-kDa and 60-kDa Ro/SS-A autoantibodies in Japanese patients with systemic sclerosis[J]. Ann Rheum Dis, 1997, 56(11):667-70.

28. Gkoutzourelas A, Liaskos C, Mytilinaiou MG, et al. Anti-Ro60 Seropositivity Determines Anti-Ro52 Epitope Mapping in Patients With Systemic Sclerosis[J]. Front Immunol, 2018, 9:2835.

29. Gkoutzourelas A, Liaskos C, Simopoulou T, et al. A study of antigen-specific anti-cytomegalovirus antibody reactivity in patients with systemic sclerosis and concomitant anti-Ro52 antibodies[J]. Rheumatol Int, 2020, 40(10):1689-1699.

30. Hudson M, Pope J, Mahler M, et al. Clinical significance of antibodies to Ro52/TRIM21 in systemic sclerosis. Arthritis Res Ther, 2012, $14(2)$ :R50.

31. Zhao J, Sun F, Li Y, et al. Significance of anti-tubulin-a-1C autoantibody in systemic sclerosis[J]. Beijing Da Xue Xue Bao Yi Xue Ban, 2020, 52(6):10091013.

32. Kwenti TE, Moye AL, Wiylanyuy AB, et al. Variation in the immune responses against Plasmodium falciparum merozoite surface protein-1 and apical membrane antigen-1 in children residing in the different epidemiological strata of malaria in Cameroon[J]. Malar J, 2017, 16(1):453.

33. Preuss B, Berg C, Dengjel J, et al. Relevance of the inner mitochondrial membrane enzyme F1F0-ATPase as an autoantigen in autoimmune liver disorders[J]. Liver Int, 2012, 32(2):249-57.

34. Corallo $\mathrm{C}$, Cheleschi S, Cutolo M, et al. Antibodies against specific extractable nuclear antigens (ENAs) as diagnostic and prognostic tools and inducers of a profibrotic phenotype in cultured human skin fibroblasts: are they functional[J]. Arthritis Res Ther, 2019, $21(1): 152$.

35. Florin L, Rubben K, Vanhaecke A, et al. Evaluation of the primary biliary cholangitis-related serologic profile in a large cohort of Belgian systemic sclerosis patients[J]. Clin Chem Lab Med, 2020, 58(3):416-423.

36. Lee S, Hayashi H, Kumagai-Takei N, et al. Clinical evaluation of CENP-B and Scl-70 autoantibodies in silicosis patients[J]. Exp Ther Med, 2017, 13(6):2616-2622.

37. Shen CY, Li KJ, Lai PH, et al. Anti-CENP-B and anti-TOPO-1-containing sera from systemic sclerosis-related diseases with Raynaud's phenomenon induce vascular endothelial cell senescence not via classical p53-p21 pathway[J]. Clin Rheumatol, 2018, 37(3):749-756.

38. Vanhaecke A, De Schepper S, Paolino S, et al. Coexistence of systemic and localized scleroderma: a systematic literature review and observational cohort study[J]. Rheumatology (Oxford), 2020, 59(10):2725-2733.

39. Zian Z, Bennani Mechita M, Hamdouch K, et al. Proteomics characterization of CENP-B epitope in Moroccan scleroderma patients with anti-centromere autoantibodies[J]. Immunol Lett, 2020, 221(09):1-5.

40. Volpe A, Ruzzenente O, Caramaschi P, et al. Clinical associations of anti-CENP-B and anti-Scl70 antibody levels measured by multiplexed fluorescent microsphere immunoassay in systemic sclerosis[J]. Rheumatol Int, 2009, 29(9):1073-9.

41. Song G, Hu C, Zhu H, et al. New centromere autoantigens identified in systemic sclerosis using centromere protein microarrays[J]. J Rheumatol, 2013, 40(4):461-8.

42. Shah AA, Xu G, Rosen A, et al. Brief Report: Anti-RNPC-3 Antibodies As a Marker of Cancer-Associated Scleroderma[J]. Arthritis Rheumatol, 2017, 69(6):1306-1312.

43. Perosa F, Favoino E, Cuomo G, et al. Clinical correlates of a subset of anti-CENP-A antibodies cross-reacting with FOXE3p53-62 in systemic sclerosis[J]. Arthritis Res Ther, 2013, 15(4):R72. 
44. Muro Y, Sugimoto K, Himeno M, et al. The clinical expression in anticentromere antibody-positive patients is not specified by the epitope recognition of CENP-B antigen[J]. J Dermatol, 1992, 19(10):584-91.

45. Ceribelli A, Isailovic N, De Santis M, et al. Detection of anti-mitochondrial antibodies by immunoprecipitation in patients with systemic sclerosis[J]. J Immunol Methods, 2018, 452(12):1-5.

46. Morozzi G, Bellisai F, Fineschi l, et al. Prevalence of anti-histone antibodies, their clinical significance and correlation with other autoantibodies in a cohort of Italian scleroderma patients[J]. Auto Immun Highlights, 2011, 2(1):29-33.

47. McMahan ZH, Cottrell TR, Wigley FM, et al. Enrichment of Scleroderma Vascular Disease-Associated Autoantigens in Endothelial Lineage Cells[J]. Arthritis Rheumatol, 2016, 68(10):2540-9.

48. Altschuler EL. Antiquity of Epstein-Barr virus, Sjögren's syndrome, and Hodgkin's disease-historical concordance and discordance[J]. J Natl Cancer Inst, 1999, 91(17):1512-3.

49. Barcelos F, Martins C, Monteiro R, et al. Association between EBV serological patterns and lymphocytic profile of SjS patients support a virally triggered autoimmune epithelitis[J]. Sci Rep, 2021, 11(1):4082.

50. Bizjak M, Selmi C, Praprotnik S, et al. Silicone implants and lymphoma: The role of inflammation[J]. J Autoimmun, 2015, 65(08):64-73.

51. Farina $A$, Cirone $M$, York $M$, et al. Epstein-Barr virus infection induces aberrant TLR activation pathway and fibroblast-myofibroblast conversion in scleroderma[J]. J Invest Dermatol, 2014, 134(4):954-964.

52. Farina A, Peruzzi G, Lacconi V, et al. Epstein-Barr virus lytic infection promotes activation of Toll-like receptor 8 innate immune response in systemic sclerosis monocytes[J]. Arthritis Res Ther, 2017, 19(1):39.

53. Farina A, Rosato E, York M, et al. Innate Immune Modulation Induced by EBV Lytic Infection Promotes Endothelial Cell Inflammation and Vascular Injury in Scleroderma[J]. Front Immunol, 2021, 12(1):651013.

54. Kasturi KN, Hatakeyama A, Spiera H, et al. Antifibrillarin autoantibodies present in systemic sclerosis and other connective tissue diseases interact with similar epitopes[J]. J Exp Med, 1995, 181(3):1027-36.

55. Moroncini G, Grieco A, Nacci G, et al. Epitope Specificity Determines Pathogenicity and Detectability of Anti-Platelet-Derived Growth Factor Receptor a Autoantibodies in Systemic Sclerosis[J]. Arthritis Rheumatol, 2015, 67(7):1891-903.

56. Sternbæk L, Draborg AH, Østerlund MT, et al. Increased antibody levels to stage-specific Epstein-Barr virus antigens in systemic autoimmune diseases reveal a common pathology[J]. Scand J Clin Lab Invest, 2019, 79(1-2):7-16.

57. Tsukamoto K, Hayakawa H, Sato A, et al. Involvement of Epstein-Barr virus latent membrane protein 1 in disease progression in patients with idiopathic pulmonary fibrosis[J]. Thorax, 2000, 55(11):958-61.

\section{Tables}

Table 3.1

Incidence of clinical symptoms in anti-Ro-52(+) SSc patients

\begin{tabular}{|c|c|c|c|c|c|c|c|c|}
\hline & $\begin{array}{l}\text { Raynaud's } \\
\text { phenomenon }\end{array}$ & $\begin{array}{l}\text { Renal } \\
\text { crisis }\end{array}$ & Cardiac & Telangiectasia & $\begin{array}{l}\text { GI } \\
\text { involvement }\end{array}$ & $\begin{array}{l}\text { Pulmonary fibrosis \& } \\
\text { PAH }\end{array}$ & $\begin{array}{l}\text { Hand } \\
\text { deformity }\end{array}$ & Arthritis \\
\hline \multicolumn{9}{|l|}{ (\%) } \\
\hline $\begin{array}{l}\text { Villalta D } \\
2012\end{array}$ & & & & & & $77.51 \%$ & & \\
\hline $\begin{array}{l}\text { Foocharoen C } \\
2017\end{array}$ & $35.30 \%$ & $1.20 \%$ & $1.20 \%$ & $21.20 \%$ & $38.80 \%$ & $44.40 \%$ & $34.10 \%$ & \\
\hline $\begin{array}{l}\text { Fujimoto M } \\
1997\end{array}$ & $90.00 \%$ & $5.00 \%$ & $4.76 \%$ & $46.67 \%$ & & $47.37 \%$ & & \\
\hline $\begin{array}{l}\text { Gkoutzourelas } \\
\text { A } \\
2018\end{array}$ & & $0.00 \%$ & & $51.43 \%$ & & $34.29 \%$ & & $37.14 \%$ \\
\hline $\begin{array}{l}\text { Gkoutzourelas } \\
\text { A } \\
2020\end{array}$ & & $0.00 \%$ & & $51.72 \%$ & $62.07 \%$ & $37.93 \%$ & & $37.93 \%$ \\
\hline $\begin{array}{l}\text { Hudson M } \\
2012\end{array}$ & & & & & & $43.81 \%$ & & \\
\hline Average(\%) & $62.65 \%$ & $1.55 \%$ & $2.98 \%$ & $42.75 \%$ & $50.43 \%$ & $47.55 \%$ & $34.10 \%$ & $37.54 \%$ \\
\hline SD & 0.27 & 0.02 & 0.02 & 0.13 & 0.12 & 0.14 & 0 & 0.01 \\
\hline
\end{tabular}


Table 3.2

Distribution of anti-Ro-52(+) SSc subtypes

\begin{tabular}{|llll|}
\hline & IcSSc & dcSSc & Sine scleroderma \\
\hline & & $(\%)$ & \\
\hline Villalta D 2012 & $73.68 \%$ & $26.32 \%$ & \\
\hline Foocharoen C2017 & $40.20 \%$ & $59.80 \%$ & \\
\hline Fujimoto M 1997 & $66.67 \%$ & $33.33 \%$ & \\
\hline Gkoutzourelas A 2018 & $65.71 \%$ & $34.29 \%$ & \\
\hline Gkoutzourelas A 2020 & $58.62 \%$ & $41.38 \%$ & \\
\hline Hudson M 2012 & $62.37 \%$ & $35.57 \%$ & $1.55 \%$ \\
\hline Average(\%) & $61.21 \%$ & $38.45 \%$ & $1.55 \%$ \\
\hline SD & 0.10 & 0.11 & 0 \\
\hline
\end{tabular}

Table 3.3

The incidence of clinical symptoms in CENP-B (+) SSc patients

\begin{tabular}{|c|c|c|c|c|c|c|c|c|c|c|}
\hline & $\begin{array}{l}\text { Pulmonary } \\
\text { fibrosis \& } \\
\text { PAH }\end{array}$ & $\begin{array}{l}\text { Raynaud's } \\
\text { phenomenon }\end{array}$ & Telangiectasia & $\begin{array}{l}\text { GI } \\
\text { involvement }\end{array}$ & $\begin{array}{l}\text { Renal } \\
\text { crisis }\end{array}$ & Cardiac & Arthritis & $\begin{array}{l}\text { Hand } \\
\text { deformity }\end{array}$ & $\begin{array}{l}\text { Diagnostic } \\
\text { Age(y) }\end{array}$ & $\begin{array}{l}\text { Disease } \\
\text { Duration(y) }\end{array}$ \\
\hline & & & & $(\%)$ & & & & & & \\
\hline $\begin{array}{l}\text { Villalta D } \\
2012\end{array}$ & $65.68 \%$ & & & & & & & & & \\
\hline $\begin{array}{l}\text { Foocharoen } \\
\text { C } \\
2017\end{array}$ & $31.60 \%$ & $36.80 \%$ & $10.50 \%$ & $42.10 \%$ & $0.00 \%$ & $10.50 \%$ & & $15.80 \%$ & & \\
\hline $\begin{array}{l}\text { Volpe A } \\
2009\end{array}$ & $4.88 \%$ & & & & & & & & & \\
\hline $\begin{array}{l}\text { Song G } \\
2013\end{array}$ & $27.30 \%$ & $90.90 \%$ & & $18.20 \%$ & $9.10 \%$ & $9.10 \%$ & $36.40 \%$ & & & \\
\hline $\begin{array}{l}\text { Shah AA } \\
2017\end{array}$ & $30.21 \%$ & & & $21.88 \%$ & & & & & 43.8 & 13.5 \\
\hline $\begin{array}{l}\text { Perosa F } \\
2013\end{array}$ & $10.67 \%$ & & & & & & & & 39.3 & 18.4 \\
\hline $\begin{array}{l}\text { Muro Y } \\
1992\end{array}$ & & $5.00 \%$ & & & & & & & 40.0 & 8.9 \\
\hline $\begin{array}{l}\text { McMahan } \\
\text { ZH } \\
2017\end{array}$ & $81.00 \%$ & & & $71.40 \%$ & $20.00 \%$ & & & & & 17.9 \\
\hline $\begin{array}{l}\text { Hanke K } \\
2010\end{array}$ & $35.70 \%$ & & & $78.60 \%$ & $2.40 \%$ & $27.40 \%$ & $51.20 \%$ & & & \\
\hline $\begin{array}{l}\text { Amor- } \\
\text { Dorado JC } \\
2008\end{array}$ & $14.29 \%$ & & $80.00 \%$ & & & $5.71 \%$ & & & 56.9 & 19.3 \\
\hline Average(\%) & $33.48 \%$ & $44.23 \%$ & $45.25 \%$ & $46.44 \%$ & $7.88 \%$ & $13.18 \%$ & $43.80 \%$ & $15.80 \%$ & 45.0 & 15.6 \\
\hline SD & 0.24 & 0.35 & 0.35 & 0.25 & 0.08 & 0.08 & 0.07 & 0 & 1.98 & 3.90 \\
\hline
\end{tabular}


Table 3.4

Distribution of anti-CENP-B(+) SSc subtypes

\begin{tabular}{|lll|}
\hline & IcSSc & dcSSc \\
\hline & $(\%)$ & \\
\hline Villalta D 2012 & $95.31 \%$ & $4.69 \%$ \\
\hline Foocharoen C2017 & $55.00 \%$ & $45.00 \%$ \\
\hline Volpe A 2009 & $92.68 \%$ & $7.32 \%$ \\
\hline Song G 2013 & $90.91 \%$ & $9.09 \%$ \\
\hline Shah AA 2017 & $93.75 \%$ & $6.25 \%$ \\
\hline Perosa F 2013 & $93.33 \%$ & $6.67 \%$ \\
\hline McMahan ZH 2017 & $90.50 \%$ & $9.50 \%$ \\
\hline Morozzi G 2011 & $77.78 \%$ & $22.22 \%$ \\
\hline McHugh NJ 1994 & $76.92 \%$ & $23.08 \%$ \\
\hline Average(\%) & $85.13 \%$ & $14.87 \%$ \\
\hline SD & 0.12 & 0.12 \\
\hline
\end{tabular}

Table 3.5

Coexistence of antibodies in SSc patients

\begin{tabular}{|lllllll|}
\hline & Ro-52 & & & \multicolumn{3}{c|}{ CENP-B } \\
\hline & Ro-60 & CENP-B & SSB/La & Scl-70 & CENP-A & Scl-70 \\
\hline Fujimoto M 1997 & $50.00 \%$ & $50.00 \%$ & $83.33 \%$ & $75.00 \%$ & & \\
\hline Gkoutzourelas A 2018 & $37.14 \%$ & $40.00 \%$ & $14.29 \%$ & $14.29 \%$ & & \\
\hline Gkoutzourelas A 2020 & $44.83 \%$ & $34.48 \%$ & & $17.24 \%$ & & \\
Hudson M 2012 & $20.62 \%$ & $32.99 \%$ & $9.28 \%$ & $9.79 \%$ & & \\
\hline Koenig M 2007 & $12.90 \%$ & $3.23 \%$ & $16.13 \%$ & $6.45 \%$ & & \\
\hline Song G 2013 & & & & & & \\
\hline Liu C 2019 & & & & $9.69 \%$ & $15.31 \%$ & \\
\hline Foocharoen C2017 & & & & $20.00 \%$ & & \\
\hline Average(\%) & $33.10 \%$ & $32.14 \%$ & $30.76 \%$ & $21.78 \%$ & $15.31 \%$ & $9.10 \%$ \\
\hline SD & 0.14 & 0.16 & 0.30 & 0.24 & 0.00 & 0.00 \\
\hline
\end{tabular}

Figures 


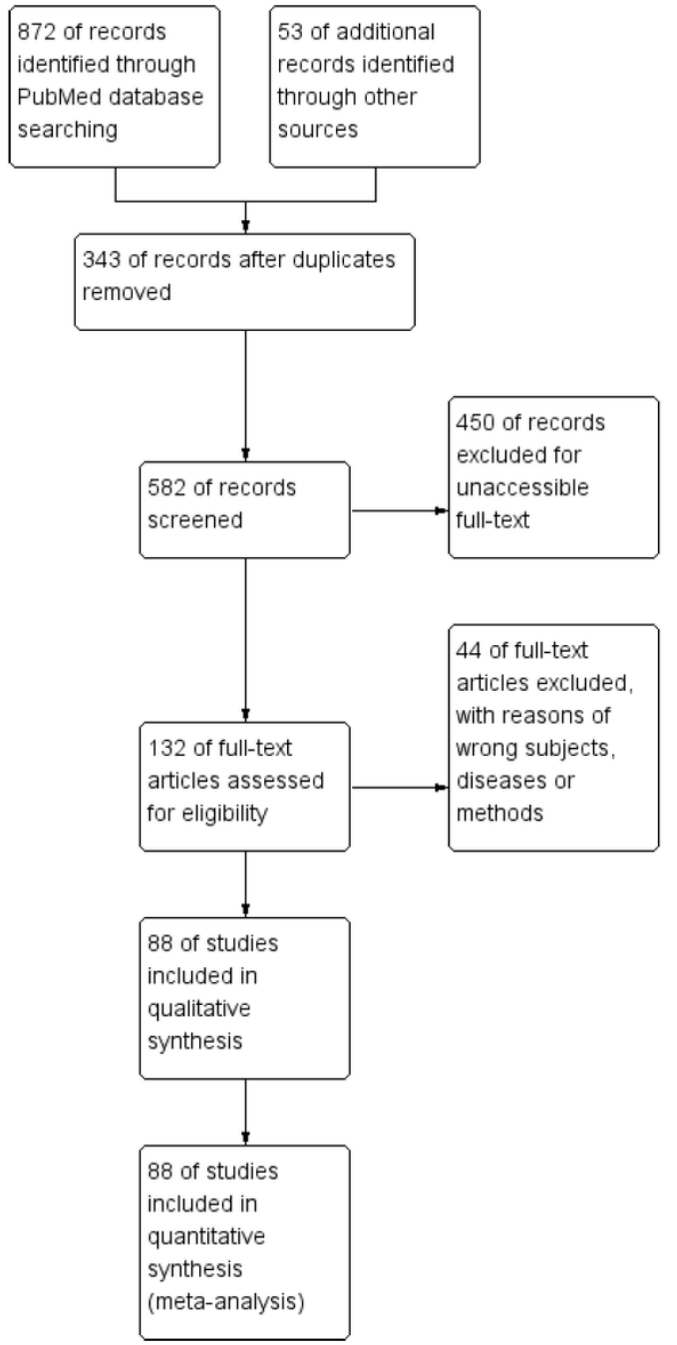

Figure 1

The flow chart of paper screening 
Anti-Ro52 Anti-La

Study or Subgroup

Ben-Eli H 2020

Bentow C 2013

Betancur JF 2018

Birnbaum J 2017

Dugar M 2010

Grossmann K 2011

Halse A 1999

Halse A2 1999

Halse AK 1996

Halse AK 2000

Manley G 1994

Nakken B 2001

Pourmand N 1999

Rönnelid J 2009

Scholz J 2015

Sillevis-Smitt $P 1996$

Tengnér $\mathrm{P} 1998$

Theander E 2015

Tishler M 1997

Trier NH 2016

Wahren M 1996

Wahren M 1997

Total $(95 \% \mathrm{Cl})$

Total events

Heterogeneity: $\mathrm{Ch}^{2}=51.77, \mathrm{df}=21(\mathrm{P}=0.0002) ;\left.\right|^{2}=59 \%$

Test for overall effect: $Z=8.86$ ( $P<0.00001$ )
Risk Ratio

M-H, Fixed, 95\% Cl

$0.95[0.69,1.32]$

$1.67[0.83,3.35]$

$3.00[1.24,7.29]$

$1.69[1.29,2.22]$

$1.56[1.22,1.99]$

$1.38[0.91,2.08]$

$1.44[0.84,2.49]$

$1.36[0.75,2.48]$

$1.33[0.67,2.67]$

$1.30[0.81,2.09]$

$2.45[0.85,7.08]$

$2.17[1.25,3.76]$

$1.05[0.81,1.36]$

$8.00[2.04,31.35]$

$2.06[1.37,3.10]$

$31.00[2.02,475.12]$

$1.14[0.69,1.90]$

$1.41[0.99,2.02]$

$1.44[0.80,2.60]$

$1.50[1.22,1.83]$

$0.64[0.33,1.24]$

$1.07[0.86,1.34]$

$1.52[1.39,1.67]$

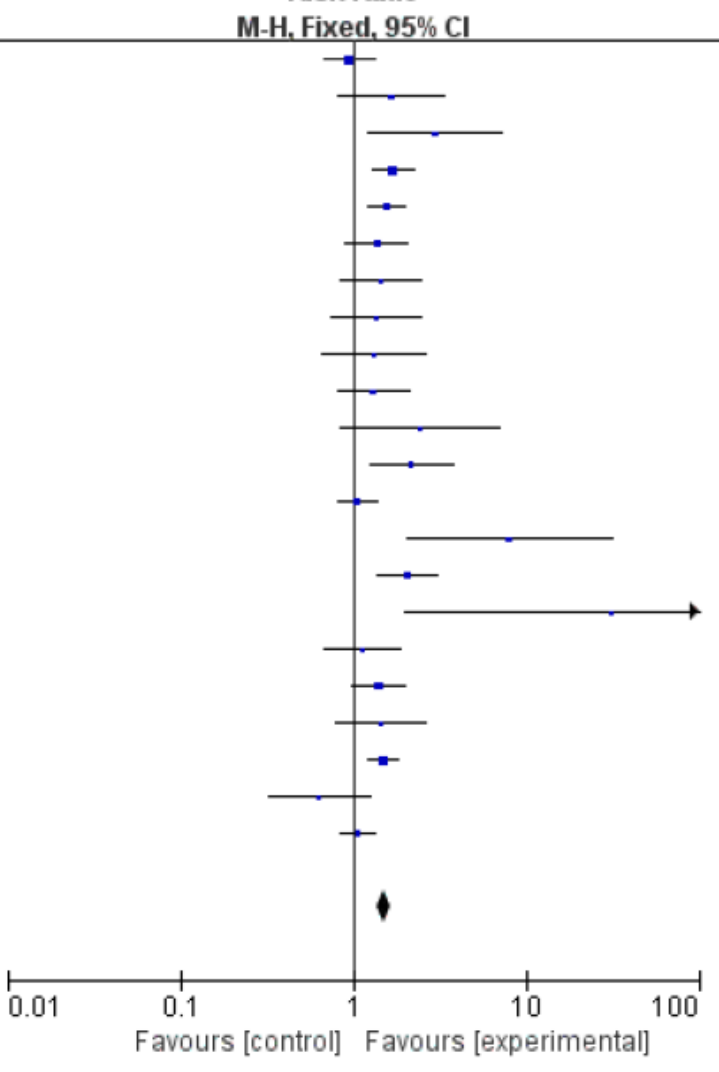

\section{Figure 2}

Forest plot of positive rates of anti-Ro-52 and anti-SSB in SS patients

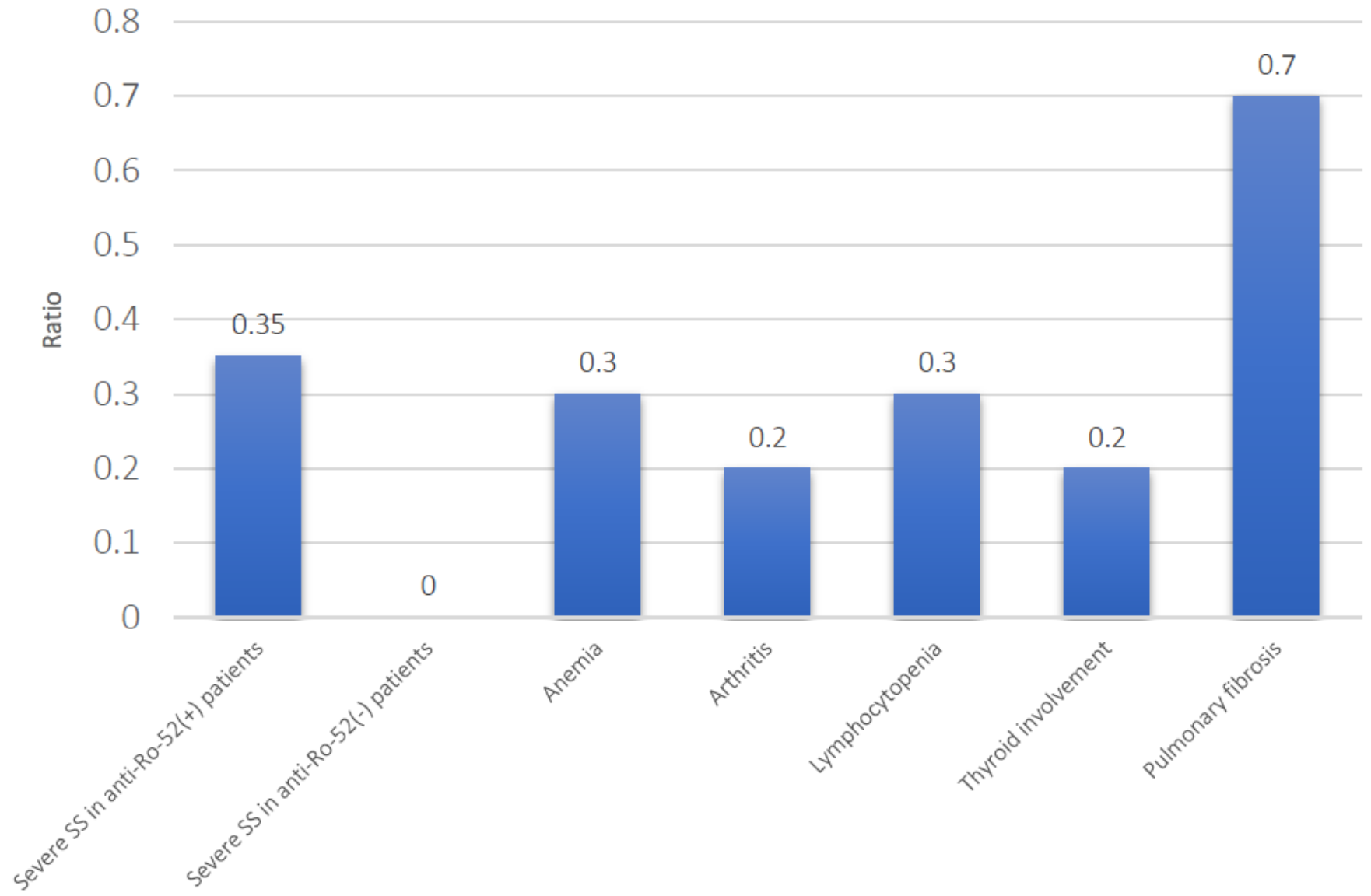


Figure 3

Histogram of the incidence of clinical symptoms in anti-Ro-52(+) SS patients

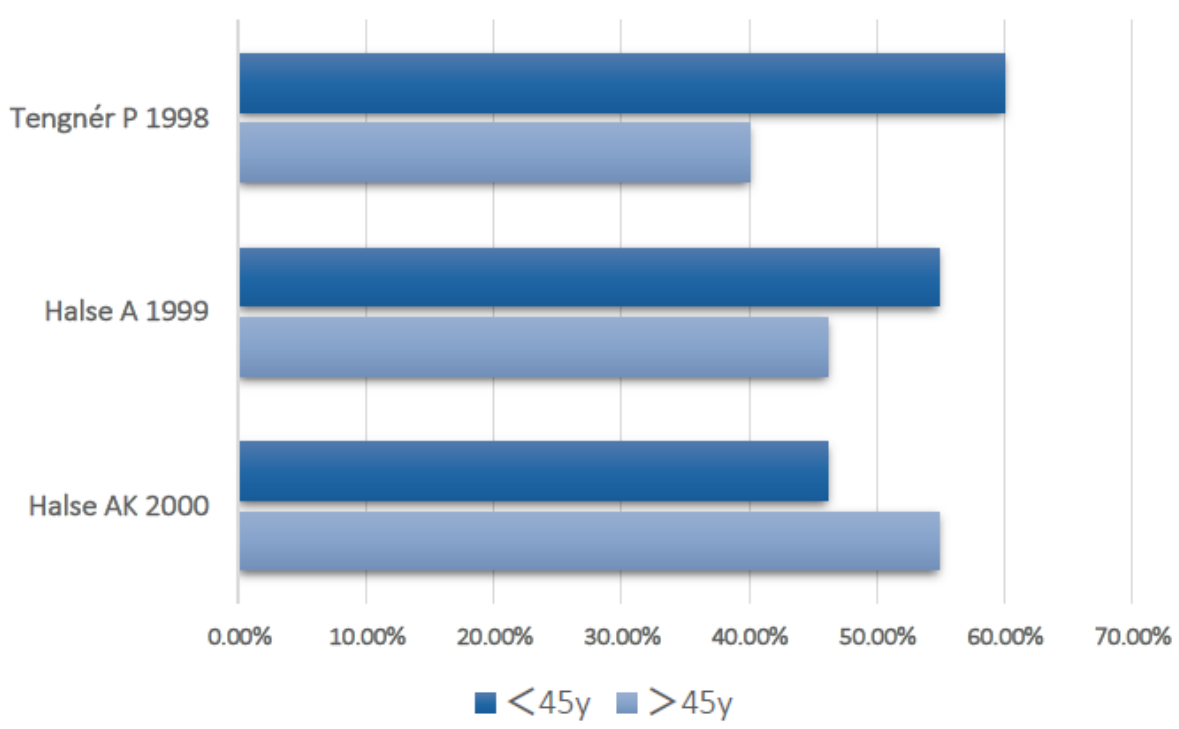

Figure 4

Histogram of age distribution in anti-Ro-52(+) SS patients

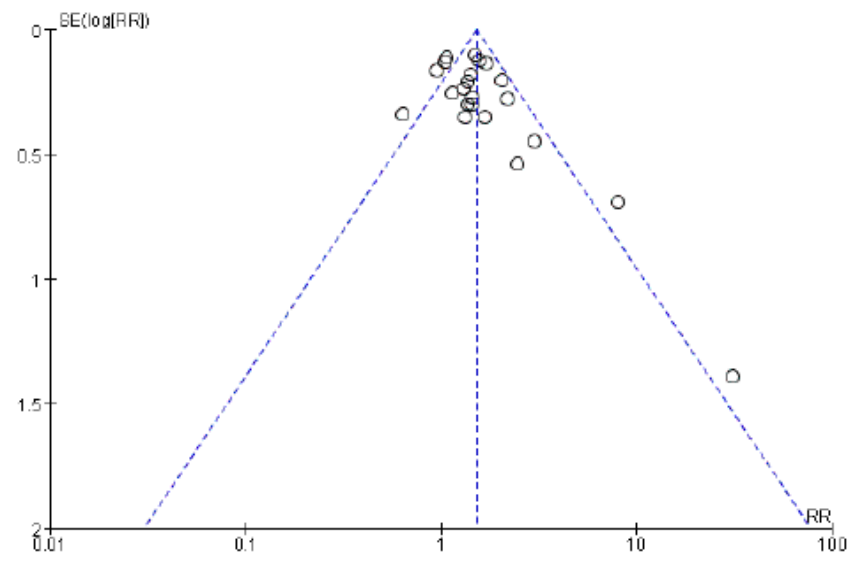

Figure 5

Funnel plot of the expression of anti-Ro-52 in SS patients

Anti CENP-B Anti-SSB

Risk Ratio

Risk Ratio

Study or Subgroup Events Total Events Total Weight M-H, Fixed, 95\% Cl

Gelber AC 2006

$\begin{array}{lll}10 & 45 & 12\end{array}$

$4575 \%$

$0.83[0.40,1.73]$

Grossmann K 2011

1972

$23 \quad 72 \quad 14.3 \%$

$0.83[0.49,1.38]$

Kajio N 2020

Muro Y 1992

986

36

$20 \quad 26$

Paween S 1998

$43 \quad 142$

Robier C 2015

ScholzJ 2015

Takeshita M 2020

Tanaka N 2017

Total $(\mathbf{9 5} \% \mathrm{Cl})$

Total events

$19 \quad 223$

$10-86 \quad 22.4 \%$

$0.25[0.13,0.49]$

$2.00[1.18,3.40]$

$\begin{array}{llll}5 & 142 & 3.1 \% & 8.60[3.51,21.08]\end{array}$

$26 \quad 223 \quad 16.2 \%$

$7 \quad 46$

$0.73[0.42,1.28]$

$0.41[0.19,0.90]$

$0.28[0.12,0.68]$

$\begin{array}{llllll}27 & 29 & 24 & 29 & 15.0 \% & 1.13[0.93,1.37]\end{array}$

781

$678100.0 \%$

Heterogeneity: $\mathrm{Chi}^{2}=61.83, \mathrm{df}=8(\mathrm{P}<0.00001) ;\left.\right|^{2}=87 \%$

Test for overall effect: $Z=0.30(P=0.77)$

$0.97[0.81,1.17]$

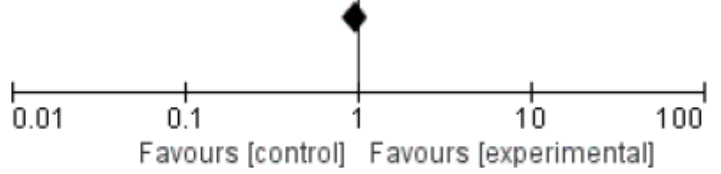


Figure 6

Forest plot of positive rates of anti-CENP-B and anti-SSB in SS patients

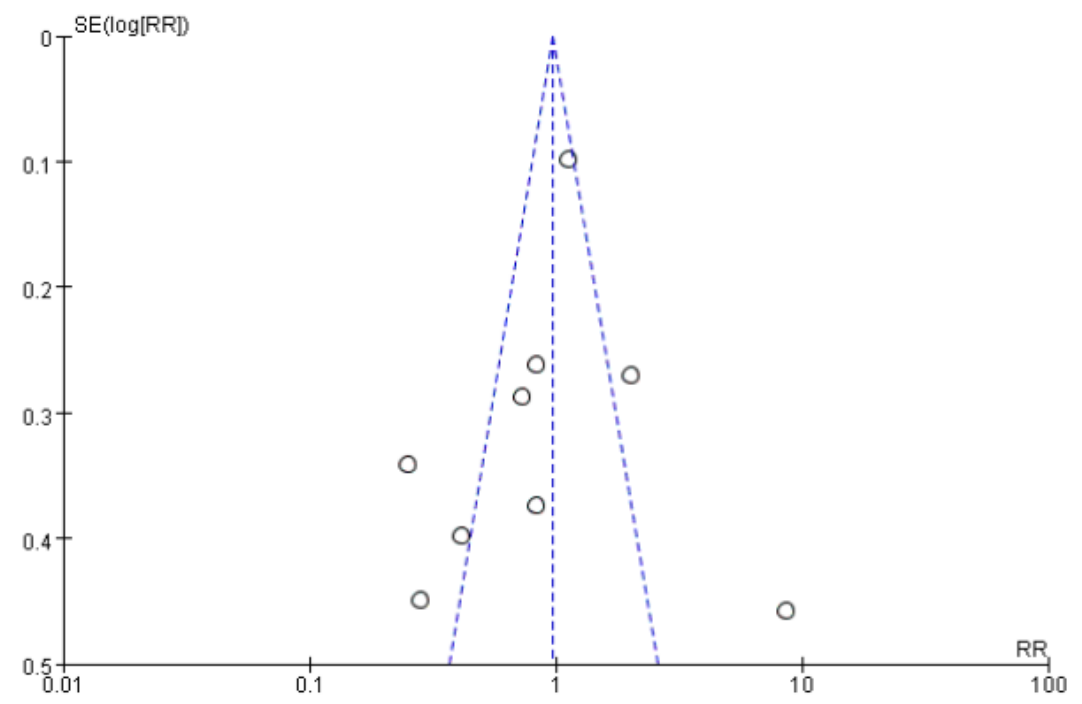

Figure 7

Funnel plot of the expression of anti-CENP-B in SS patients

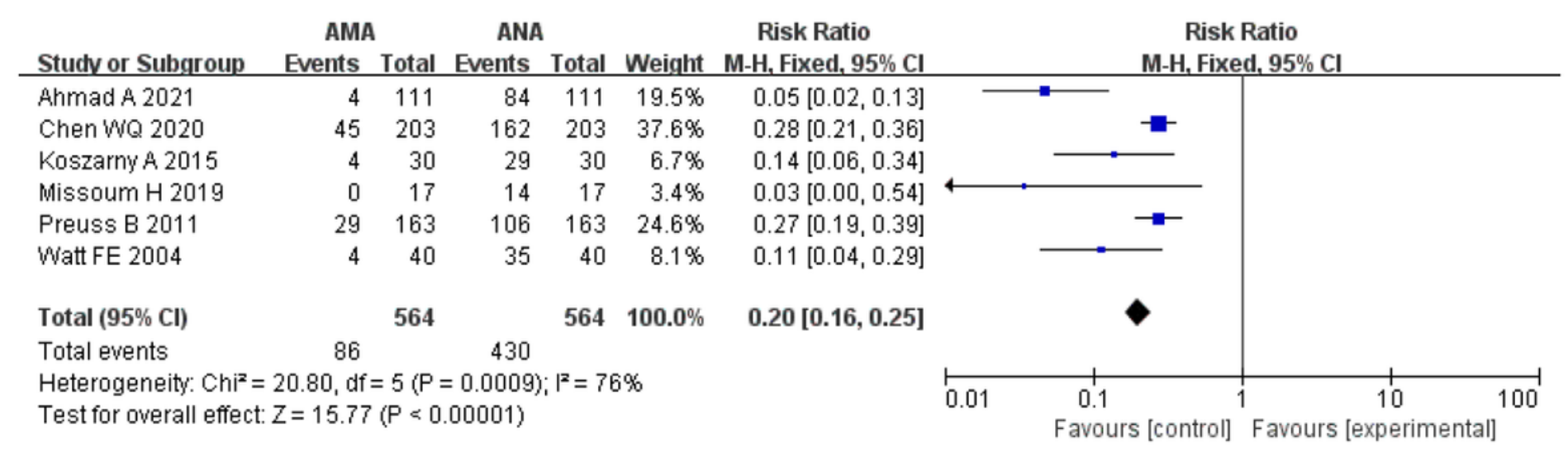

Figure 8

Forest plot of positive rates of AMA and ANA in SS patients 
Anti-Ro-52 Anti-SSB/Anti-Scl-70

Risk Ratio

Risk Ratio

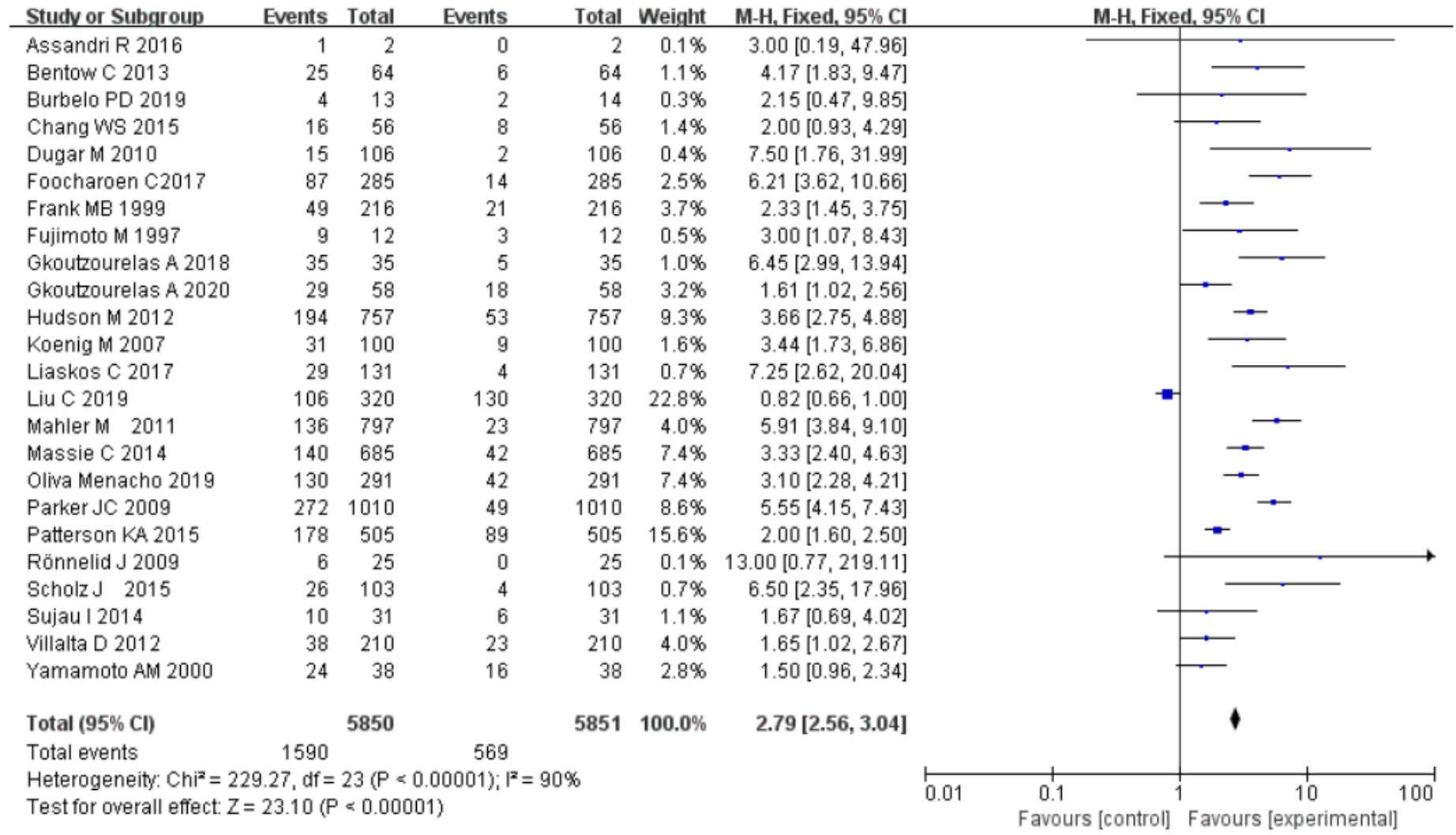

\section{Figure 9}

Forest plot of positive rates of anti-Ro-52 and anti-SSB/anti-Scl-70 in SSc patients

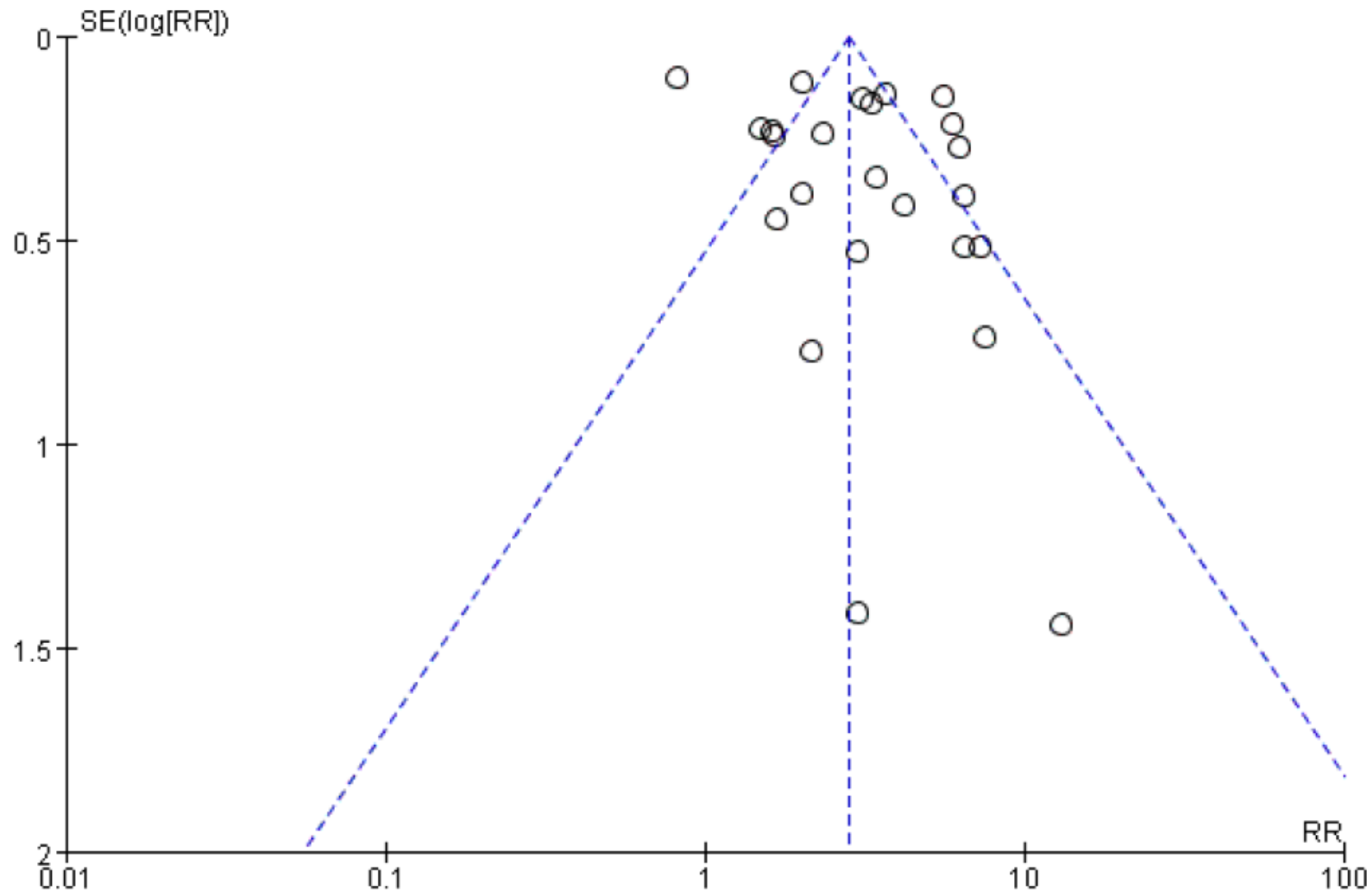




\section{Figure 10}

Funnel plot of the expression of anti-Ro-52 in SSc patients

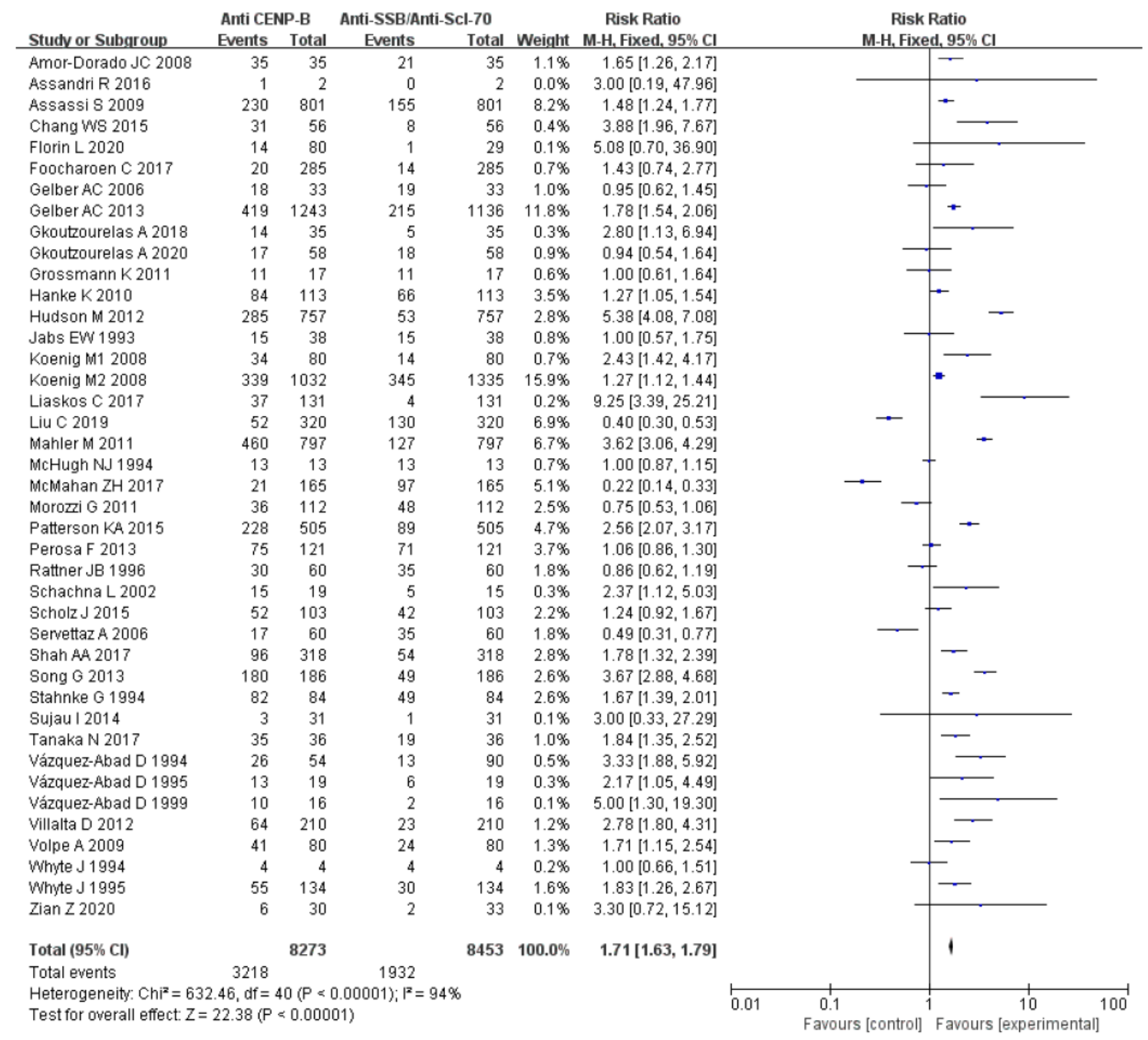

\section{Figure 11}

Forest plot of positive rates of anti-CENP-B and anti-SSB/anti-Scl-70 in SSc patients

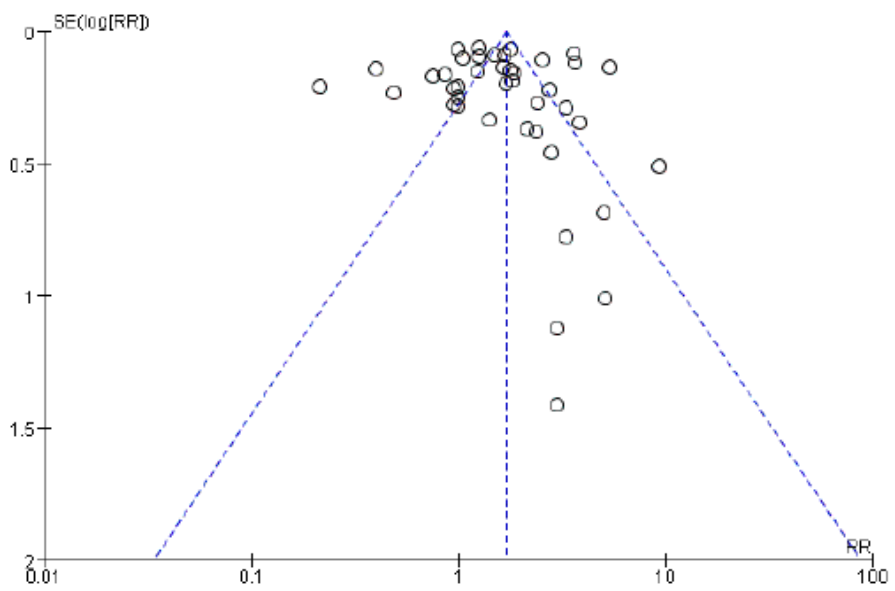

Figure 12

Funnel plot of the expression of anti-CENP-B in SSc patients 
AMA

ANA

Studv or Subgroup

Assassi 82009

Ceribelli A 2018

Corallo C 2019

Missoum H 2019

Skare TL 2011

Whyte J 1994

Zian Z 2020

Total $(95 \% \mathrm{Cl})$

Total events

Heterogeneity: $\mathrm{Ch}^{2}=237.37, \mathrm{df}=6(\mathrm{P}<0.00001) ;\left.\right|^{2}=97 \%$

Test for overall effect: $Z=18.87(P<0.00001)$

9 801

813

$20 \quad 184$

046

$6 \quad 63$

34

280

1191

$1191 \quad 859$

613

129

$36 \quad 46$

$4 \quad 4 \quad 0.5 \%$

$73 \quad 80 \quad 8.5 \%$

$1036100.0 \%$

Risk Ratio

nts Total Weight $\mathrm{M}-\mathrm{H}$, Fixed, 95\% Cl

$0.7 \%$

$0.2 \%$

$4.2 \%$

$63 \quad 0.5 \%$

$0.01[0.01,0.02]$

$1.33[0.64,2.76]$

$3.15[0.44,22.60]$

$0.01[0.00,0.22]$

$1.50[0.44,5.06]$

$0.78[0.41,1.48]$

$0.03[0.01,0.11]$

4

0.04 [0.03, 0.06]

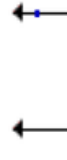

Risk Ratio

M-H, Fixed, 95\% Cl

\section{Figure 13}

Forest plot of positive rates of AMA and ANA in SSc patients

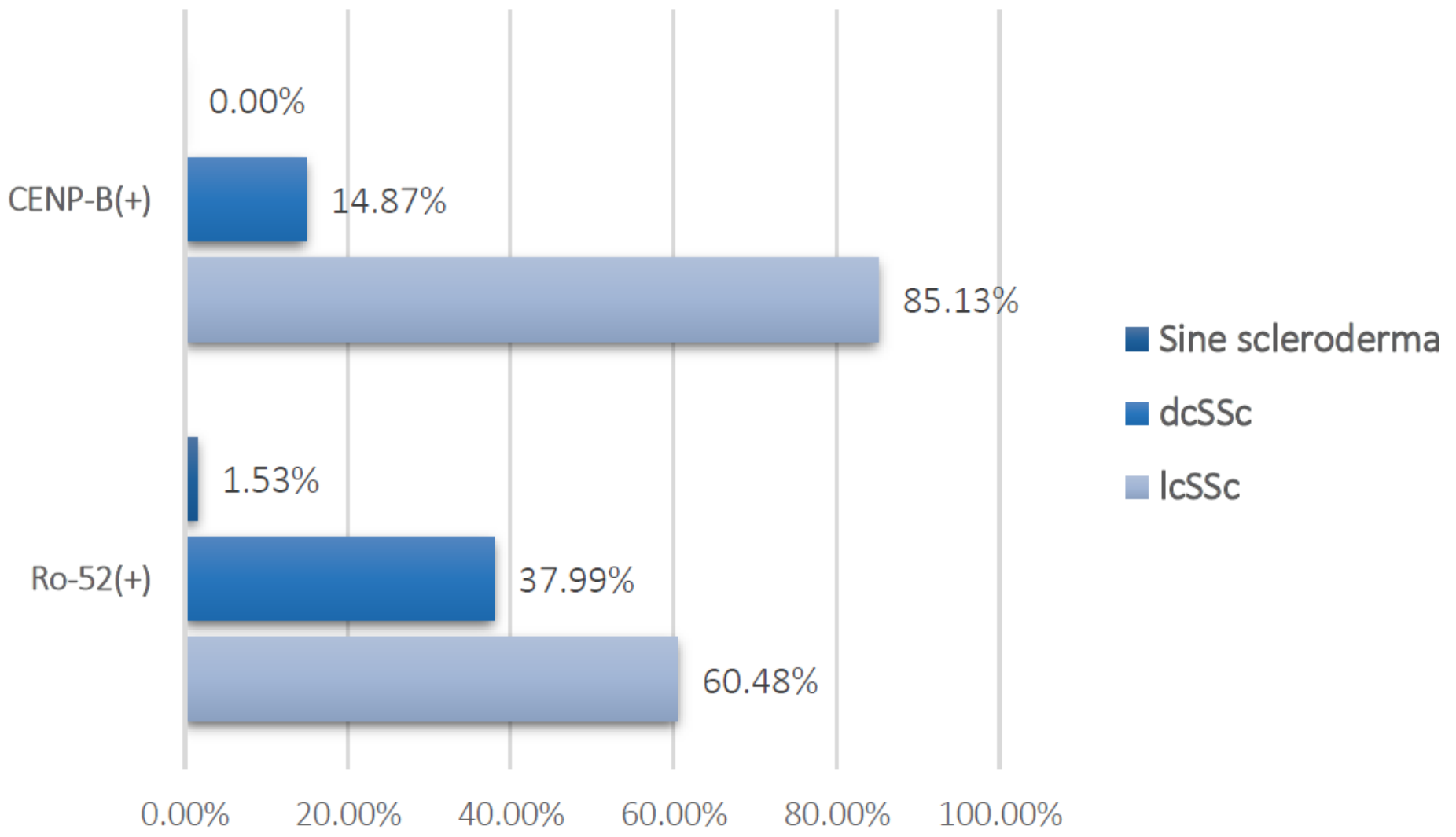

Figure 14

Distribution of disease types in anti-Ro-52(+) and anti-CENP-B(+) SSc patients 